\title{
Finding the right title for your article: Advice for academic authors
}

\author{
van Teijlingen E1-5, Ireland J6,7, Hundley V8, Simkhada P4-6, 9, Sathian B10,11
}

${ }^{1}$ Professor, School of Health \& Social Care, Bournemouth University, Bournemouth, UK.

${ }^{2}$ Honorary Visiting Professor, London Metropolitan University, London.

${ }^{3}$ Honorary Professor, University of Aberdeen, UK.

${ }^{4}$ Visiting Professor, Manmohan Institute of Health Science and Nepal Institute of Health Science, Tribhuvan University, Nepal.

5Visiting Professor, Nobel College, Pokhara University, Kathmandu, Nepal.

6Visiting Fellow, Bournemouth University, UK.

${ }^{7}$ Community Midwife \& Visiting Fellow, Poole Foundation NHS Trust \& Bournemouth University, UK.

8Professor of Midwifery, Bournemouth University, United Kingdom

${ }^{9}$ Senior Lecturer in International Health, School of Health and Related Research (ScHARR), University of Sheffield, Sheffield.

10Assistant Professor, Department of Community Medicine, MCOMS, Nepal

11 President CEA, INEA, ATRFCE

\section{Chief Editor}

\section{Dr. Pradeep Aggarwal}

Technical Editor

Dr. Nishida Chandrasekharan

Formatting Editor

Dr. Abhilash E S
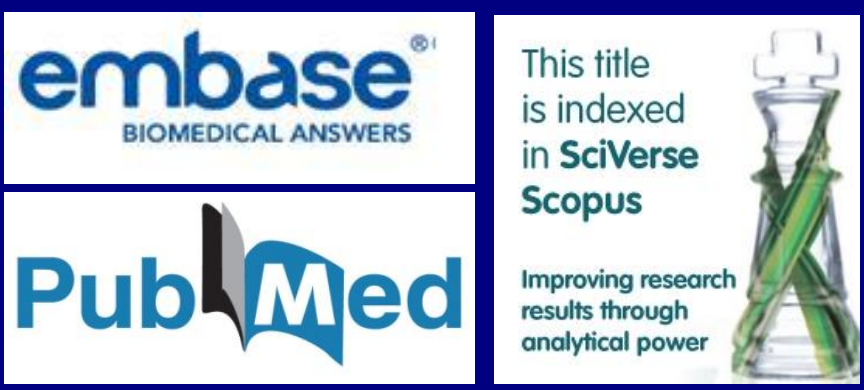

\section{Short Communication}

\section{Corresponding Author:}

Dr. Edwin van Teijlingen

Professor, School of Health \& Social Care, Bournemouth University, Bournemouth, UK.

E-mail: evteijlingen@bournemouth.ac.uk

\section{Abstract}

On reading the title of an article the reader can sometimes wonder what the author is trying to say, as the title seems so far removed from the research covered in the article. Do such authors forget that many readers of health and medical journals browse the list of contents (in a paper or electronic format) and use titles to select the article that attracts attention? Academic authors are often not clear 
enough in the titles of their articles, and hence may not attract as large a readership as possible. Any author would want their article to be read and cited, and to stand out in a crowded Table of Contents or a list of papers found in a search on electronic databases.

Keywords: Title, Scientific writing, Visibility, Citation.

\section{Background}

On reading the title of an article the reader can sometimes wonder what the author is trying to say, as the title seems so far removed from the research covered in the article. Do such authors forget that many readers of health and medical journals browse the list of contents (in a paper or electronic format) and use titles to select the article that attracts attention? Academic authors are often not clear enough in the titles of their articles, and hence may not attract as large a readership as possible. Any author would want their article to be read and cited, and to stand out in a crowded Table of Contents or a list of papers found in a search on electronic databases. It is worth remembering that Druss and Marcus found that the number of MEDLINE articles increased from approximately 272,344 in 1978 to a staggering 442,756 per annum in $2001^{1}$. Any article competes with this enormous volume of work and somehow it must stand out amongst all these millions of papers published globally. Our take-home message is that you must select the words in the title in such a way that it attracts attention otherwise your article will not get the visibility and citations it deserves.

\section{Sub-optimal article titles}

There are a number of ways of making a title less attractive and less useful. First, there are titles with insufficient information, secondly titles, with the wrong, cryptic or vague information, and finally titles which are far too long with too much information ${ }^{2}$.

\section{Too short titles}

Sometimes we find papers with very short ambiguous titles which fail to give any detail, for example 'Erectile dysfunction' by Shamloul and Ghanem ${ }^{3}$. This title does little to inform the reader as to whether the paper reports primary research or a review, or whether the topic is approached as (a): a clinical problem; (b) an epidemiological measurement issue; or (c) a psychological problem. The paper 'Association of BMI on Systolic and Diastolic Blood Pressure in Normal and Obese Children' in this journal is rather short, just 14 words, but more importantly fails to mention the study design and the study setting/ location 4 . Attracting similar criticism is the title 'Assessment of immunization Status of Children between 12-23 months in Bareilly District' also recently published in the Nepal Journal of Epidemiology 5 . The latter title does not mention the study design, and the time frame is rather ambiguous. Do the authors mean: (a) immunization status at 12-23 months (i.e. status as measured 12 to 23 months after immunization)? or (b) in children aged 12 to 23 months?
Another short title, 'The old, old story - through song' appeared recently in a midwifery journal ${ }^{6}$ it leaves the reader wondering: 'What old story exactly?' However, such a title could intrigue a reader searching widely on the subject of 'singing' and 'song'.

\section{Non-descriptive titles}

Occasionally one comes across titles that are vague and non-descriptive, for example 'Perceptions and effects of antenatal education' ${ }^{7}$. This vague title begs the questions: (a) whose perceptions, those of midwives, doctors, policymakers, the general public?; and (b) effects on whom? Do the authors refer to health effects on pregnant women, long-term psycho-social effects on babies, job satisfaction of maternity care providers delivering antenatal education? Another example is Eshner's paper from more than a century ago: 'A graphic study of tremor' ${ }^{8}$. What kind of tremor is this research about: medical research into unintentional muscle movements or the geological study of earthquakes? One of our own previous titles ${ }^{9}$ was perhaps a little too clever: 'Maternity satisfaction studies and their limitations: "What is, must still be best"' as the title only really makes sense to people who know the short paper by Porter and Macintyre ${ }^{10}$ 'What is, must be best: A research note on conservative or deferential responses to antenatal care provision' to which the 'still' in the title refers.

Some papers have interesting and/or catchy titles, perhaps more so in the social sciences than in health journals. Sometimes these catchy titles are just too cryptic, for example from 'On a train Morgantown: A film script' ${ }^{11}$ and from the same author 'How Did I Get to Princess Margaret? (And How Did I Get Her to the World Wide Web?)'12 ${ }^{12}$ For both papers one needs to read the paper to understand the title. So before suggesting a funny title, remember that articles with funny titles are less cited than more traditional ones as an analysis of papers published in psychology journals suggested ${ }^{13}$.

\section{Too long titles}

Journal article titles have been getting longer over the past half century, for example in sociology ${ }^{14}$. Longer titles, however, are not without their problems, for example they can put off some potential readers. Some may think the author is pretentious or that the paper will be hard to read as the title is hard to comprehend. Longer titles give more details about the study, its scope, population, geographical location, theoretical underpinning and/or methods used, but the title should not be a complex sentence, or worse sentences. There are plenty of examples of titles which are too long: 'Trends in College Binge Drinking During a Period of Increased Prevention Efforts: Findings from 4 Harvard School of Public Health College Alcohol Study Surveys: 1993-2001'15 or 'Geocoding and monitoring of US socioeconomic inequalities in mortality and cancer incidence: does the choice of area-based measure and geographic level matter? The Public Health Disparities Geocoding Project' ${ }^{16}$ or 'A phase 3, double-blind, randomised, parallel-group, placebo-controlled study of oral weekly alendronate for the prevention of androgen 
deprivation bone loss in nonmetastatic prostate cancer: the Cancer and Osteoporosis Research with Alendronate and Leuprolide (CORAL) study' ${ }^{17}$. The latter title is so full of unnecessary details that is hard for the reader to understand what its key focus is.

The next paper title 'A study of pneumococci: a comparison between the pneumococci found in the throat secretions of healthy persons living in both city and country and those obtained from pneumonic exudates and diseased mucous membranes $^{18}$ is not only too long but also makes the mistake of repeating the word 'pneumococci'. As the latter paper was published over a century ago it indicates that having too long titles is not a recent phenomenon.

\section{Existing guidance}

There is some useful information available to authors, as many journals provide some advice on article titles. For example The International Journal of Epidemiology stipulates: "Titles should be short and specific. Subtitles may be used to amplify the main title" (www.oxfordjournals.org/our_journals/ije/for_authors/gen eral.html). Whilst the PRISMA guidance on reporting systematics reviews gives 27 guidelines of which the first one relates to the title: 'Identify the report as a systematic review, a meta-analysis or both ${ }^{\prime 19}$. Obviously PRISMA is only concerned with systematic reviews and meta-analyses, but the general message is to list the research method in the article's title.

Wiley-Blackwell, publisher of many journals including the $B J O G$, has some good advice under the heading 'Optimizing Your Article for Search Engines'. The first step is to "Construct a clear, descriptive title", because a "search engine assumes that the title contains all of the important words ... and thus weights words appearing there most heavily. This is why it is crucial for you to choose a clear, accurate title. Think about the search terms that readers are likely to use when looking for articles on the same topic as yours, and help them by constructing your title to include those

terms"

(http://authorservices.wiley.com/bauthor/seo.asp ). This is also the reason why your key words for an article, should you be asked to provide these, need to be words different from the ones listed in your title.

Following on from the above advice, we have listed a few (hopefully) useful tips:

- Read widely and pay attention to the titles you come across during your scientific reading.

- Seek advice about titles from colleagues with more experience in the field.

- Attend medical conferences and clinical meetings to increase your knowledge and to get it touch with good studies and titles.

- A good title should give the information about place, general setting and type of the study and should link to your study aims and objectives. The optimum number of words in a title should be roughly between 10 and 15 . Titles do not necessarily need to contain a verb. Write down a few titles; revise them until you get a few suitable ones (see Box 1).

- Present draft papers to colleagues and students and discuss all aspects including the possible titles.

- Try not to use abbreviations in titles unless the abbreviation is widely known, such as USA, HIV or BMI. For example, the title of a recent letter in the Nepal Journal of Epidemiology was 'Increasing ADR reporting in Nepal', this does not mean much to somebody who does not know what ADR stands for ${ }^{20}$.

- If you plan to use a catchy title consider including a subtitle to give useful information, for example: 'Parting the clouds: A vision of supervision of midwifery' ${ }^{21}$.

- Nepali researchers have the added difficulty of having to formulate the article title in English, and some may struggle a little with this. It is a good idea to ask a native English-speaking academic to have a look at your title and preferably your whole final draft of your paper.

\section{BOX 1 Example on how to construct a title}

Write down the key words that describe your study randomly and move them around in different ways to help construct a title. For example, your research on midwives and their views of pregnant women who are sight impaired could include the words: Midwives, attitudes, blind, the study method (cross-sectional survey, interviews, focus groups, questionnaire survey, etc.), or the locality Thus we may end up with some of the following possible titles:

- Blind to disability: A qualitative study of midwives' perceptions of sight-impaired pregnant women.

- Midwives' attitudes towards blind women in pregnancy: Focus groups in New York.

- Midwives who cannot see the problem: A phenomenological study of midwives' interactions with blind pregnant women.

\section{Conclusion}

While a catchy title can help get readers to look at your paper, it will not turn a bad paper into a good one. Although your title is the first sentence the reader sees, it should be written after you have completed the article, i.e. once you have a firm sense of your paper's structure and contents. Remember, your title should be 'selling' your article to potential readers and at the same time accurately describing the contents of the paper.

\section{Author's Contribution:}

EvT had the original idea and drafted the manuscript. The manuscript was revised by $\mathrm{Jl}, \mathrm{VH}, \mathrm{PS}$ and BS. All agreed the final version.

\section{Conflict of interest:}

There is no conflict of interest among authors arising from the study. 


\section{References}

1. Druss BG, Marcus SC. Growth and decentralization of the medical literature: implications for evidence-based medicine J Med Libr Assoc. 2005; 93(4): 499-501. PMid:16239948 PMCid:PMC1250328

2. Simkhada $P$, van Teijlingen $E$, Hundley $V$, Simkhada BD. Writing an Abstract for a Scientific Conference, Kathmandu Univ Med J. 2013; 43(3): 262-265.

3. Shamloul R, Ghanem H. Erectile dysfunction, Lancet. 2013; 381(9861):153-65.

http://dx.doi.org/10.1016/S0140-6736(12)60520-0

4. Gundogdu Z. Association of BMI on Systolic and Diastolic Blood Pressure in Normal and Obese Children, Nepal J Epidemiol. 2011; 1(3): 101-105.

5. Joshi HS, Gupta R, Singh A, Mahajan V. Assessment of immunization Status of Children between 12-23 months in Bareilly District, Nepal J Epidemiol. 2011; 1(2): 47-50.

http://dx.doi.org/10.3126/nje.v1i2.5091

6. Ireland J, Oakland J. The old, old story - through song. Essentially Midirs 2013; 4(9): 17-22.

7. Al-Ateeq MA, Al-Rusaiess AA, Al-Dughaither AA.

Perceptions and effects of antenatal education, Saudi Med

J. 2013; 34(12): 1287-1293.

PMid:24343470

8. Eshner AA. A graphic study of tremor, J Exp Medicine. 1897; 2(3): 301-12.

http://dx.doi.org/10.1084/jem.2.3.301

PMid:19866834 PMCid:PMC2117941

9. van Teijlingen E, Hundley V, Rennie A-M, Graham W, Fitzmaurice A. Maternity satisfaction studies and their limitations: "What is, must still be best", Birth 2003; 30: 7582.

http://dx.doi.org/10.1046/j.1523-536X.2003.00224.x PMid:12752163

10. Porter $M$, Macintyre S. What is, must be best: $A$ research note on conservative or deferential responses to antenatal care provision. Soc Sci Med. 1984; 19: 11971200.

http://dx.doi.org/10.1016/0277-9536(84)90370-8

11. Jones K. On a train from Morgantown: A film script.

Psychol Stud. 2012; 57(2): 224-235.

http://dx.doi.org/10.1007/s12646-011-0123-9

12. Jones K. How Did I Get to Princess Margaret? (And How Did I Get Her to the World Wide Web?). Forum: Qualitative Soc Res. 2007; 8(3): 3.

13. Sagi I, Yechiam E. Amusing titles in scientific journals and article citation. J Inf Sci. 2008; 34(5): 680-687. http://dx.doi.org/10.1177/0165551507086261

14. Moody J. Trends in Sociology Titles, Am Sociol 2006. 37:77-80.

http://dx.doi.org/10.1007/s12108-006-1016-6

15. Wechsler $H$, Lee J E, Kuo M, Seibring M, Nelson T F, Lee $\mathrm{H}$. Trends in college binge drinking during a period of increased prevention efforts: Findings from 4 Harvard School of Public Health College Alcohol Study surveys: 1993-2001. J Am Coll Health. 2002; 50(5): 203-217. http://dx.doi.org/10.1080/07448480209595713 PMid:11990979

16. Krieger N, Chen J T, Waterman P D, Soobader M J, Subramanian S V, Carson R. Geocoding and monitoring of US socioeconomic inequalities in mortality and cancer incidence: does the choice of area-based measure and geographic level matter? The Public Health Disparities Geocoding Project. Am J Epidemiol. 2002; 156(5): 471-482. http://dx.doi.org/10.1093/aje/kwf068

PMid:12196317

17. Klotz LH, McNeill IY, Kebabdjian M, Zhang L, Chin JL, Canadian Urology Research Consortium. A phase 3, doubleblind, randomised, parallel-group, placebo-controlled study of oral weekly alendronate for the prevention of androgen deprivation bone loss in nonmetastatic prostate cancer: the Cancer and Osteoporosis Research with Alendronate and Leuprolide (CORAL) study. Eur Urol. 2013; 63(5):927-35. http://dx.doi.org/10.1016/j.eururo.2012.09.007 PMid:23040208

18. Park WH, Williams AW, Oppenheimer A, Bolduan C, Berry J L, Assersen MA, Lowden, M, van Giesen I. A study of pneumococci: a comparison between the pneumococci found in the throat secretions of healthy persons living in both city and country and those obtained from pneumonic exudates and diseased mucous membranes J Exp Med. 1905; 7(5): 403-419. http://dx.doi.org/10.1084/jem.7.5.403 PMid:19867007 PMCid:PMC2124585

19. Moher D, Liberati A, Tetzlaff J, Altman DG, The PRISMA Group. Preferred Reporting Items for Systematic Reviews and Meta-Analyses: The PRISMA Statement. Open Med. 2009; 3(3): 123-130.

20. Shankar RP. Increasing ADR reporting in Nepal, Nepal J Epidemiol. 2013; 3(2): 252.

http://doi.dx.org/10.3126/nje.v3i2.8511

21. Leamon J, Ireland J. Parting the clouds: A vision of supervision of midwifery. Practising Midwife. 2013; 16(1): 12-14.

PMid:23431661

Article Information

Article history

Received $10^{\text {th }}$ January 2014

Received in revised form $20^{\text {th }}$ March 2014

Accepted $25^{\text {th }}$ March 2014 